Research Paper:

\title{
Motivations to Use Mobile Virtual Social Networks and Their Related Social Capital Among College Students: A Cross-sectional Study
}

Majid Barati ${ }^{1}$ (D) Fatemeh Heidari-Moghis ${ }^{2}$, Babak Moeini ${ }^{1}$ (D), Mohammad Babamiri ${ }^{3}$ (D), Maryam Afshari ${ }^{*}$ (D), Mohammadhasan Saati-Asr ${ }^{2}$ (D), Ghazaleh Kalantarnia ${ }^{2}$, Saba Eslami², Atefe Ostad-Abdollahpour ${ }^{2}$

1. Social Determinants of Health Research Center, Hamadan University of Medical Sciences, Hamadan, Iran.

2. Department of Public Health, School of Health, Hamadan University of Medical Sciences, Hamadan, Iran.

3. Department of Ergonomics, School of Health, Research Center for Health Sciences, Hamadan, University of Medical Sciences, Hamadan, Iran.

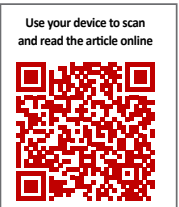

Citation Barati M, Heidari-Moghis F, Moeini B, Babamiri M, Afshari M, Saati-Asr M, Kalantarnia G, Eslami S, Ostad-Abdollahpour A. Motivations to Use Mobile Virtual Social Networks and Their Related Social Capital Among College Students: A Cross-sectional Study. Avicenna J of Neuropsychophysiology. 2018; 5(4):151-158. http://dx.doi.org/10.32598/ajnpp.4.3.265

loi http://dx.doi.org/10.32598/ajnpp.4.3.265

\section{(c) (i) (5)}

Article info:

Received: 24 Apr 2018

Accepted: 10 Sep 2018

Available Online: 01 Nov 2018

Keywords:

Internet, Social capital,

Students, Iran

\section{A B S T RACT}

Introduction: Due to the increasing use of virtual networks and, on the other hand, ambiguities towards the positive or negative effects of these networks on the level of social interaction and social capital of users.

Objectives: This study aims to determine the relationship between the motivation to use virtua mobile networks and social capital among students of Hamadan University of Medical Sciences.

Materials and Methods: This was a cross-sectional study carried out on 350 students of Hamadan University of Medical Sciences in 2017. The participants were selected by a stratified sampling method with the proportional assignment. Data gathering tools included the demographic form and questionnaires of motivation to use virtual networks and social capital. The subjects completed the tools through the self-reporting. The obtained data were analyzed by the Pearson correlation test and linear regression in SPSS V. 24.

Results: Most students (42.6\%) used virtual networks 3-5 hours per day. Entertainment and pastime were the most reported reasons and motivations for using the virtual networks among students with $59 \%$ and $58.8 \%$ of the maximum achievable score, respectively. There was a positive and significant correlation between bonding and bridging social capital and the rate of virtual network usage. Among the related factors studied, gender, nativeness, self-disclosure, immersion in the media, pastime, information search, individual status, maintaining relationships, entertainment, and linking social capital have significant roles in explaining the variance of the motivation to use the virtual network among the students $(P<0.05)$

Conclusion: Further research is needed in this area because students increasingly use virtual networks and they are unfamiliar with other aspects of these networks affecting their health and life. University counseling centers should provide the required training based on the facts for the students about the positive and negative consequences of using virtual networks.

\footnotetext{
* Corresponding Author:

Maryam Afshari, PhD.

Address: Department of Public Health, School of Health, Hamadan University of Medical Sciences, Hamadan, IR Iran.

Tel: +98 (81) 38380090
}

E-mail: afshari_m20@yahoo.com 


\section{Introduction}

$\mathrm{n}$ the $21^{\text {st }}$ century, virtual networks have become popular throughout the world and turned into one of the most important ways of communication [1]. Virtual social networks are calling patterns in which interactions and connections between network agents are supported by a technical base and internet infrastructure [2]. In these networks, the purpose, interest, or common needs can be bonding elements that simulate the living in a real community, even in the absence of a physical appearance [3].

According to statistics, the total number of Internet users in the world was about 1.2 billion in 2000, which increased to 17.7 billion in 2015 [4]. These statistics are slightly different in Iran. According to available statistics, there are over 56.7 million internet users in Iran, which places Iran at the top of the Internet user countries in the Middle East [5]. Besides, the results of studies conducted in our country indicate that the average time spent on the use of the internet is 52 minutes a week, which reaches 57 minutes for people aged 21-24 years [6].

Researchers declared that internet usage improves interpersonal relationships with advanced technologies and enhances social networking. One of the greatest potentials of the internet is its ability to extend beyond the limits of space and time and provides a virtual location for meeting so that the individuals can maintain their social relationships with others [7]. The Internet allows people to face a mass audience by expanding the boundaries of social networking from real life to virtual spaces; thus, it fosters global interactions among peoples with common interests [8].

Therefore, the membership in virtual social networks and its impact on the social relationships of individuals or, in other words, social capital is evident. Researchers believe that virtual social networks have changed the communication channels in today's world, and increasing the social relationships in online and offline environments have expanded the social capital of users [9]. Research shows that social capital affects several nonspecific incomes and increases the happiness of people's lives. These findings suggest that having positive relationships with individuals improves life satisfaction and even increases the social capital among individuals [10].

Massari et al. reported that the users enter the virtual networks to maintain the existing social relationships, to find new friends and partners, and to share experiences. According to the findings of the Chosunil et al., easy access, simple use, no time limit even overnight, and anonymity of users are the reasons for using the virtual networks [11].

Considering the increasing use of virtual networks and the uncertainties about the positive or negative effects of these networks on the level of social interaction and social capital of users, we aimed to determine the motivation to use mobile virtual networks and social capital among students of Hamadan University of Medical Sciences.

\section{Materials and Methods}

The present study was a cross-sectional study conducted on 350 students of Hamadan University of Medical Sciences from April to June 2017. The statistical population consisted of students studying at different faculties of Hamadan University of Medical Sciences. The sample size was calculated based on a $95 \%$ confidence level, a precision of $5 \%$, and the use rate of a virtual social network as $65 \%$. Assuming the values derived from the Hasanzadeh study [12], a sample of 350 students were considered.

Sampling was done by stratified random sampling with proportional allocation. First, the list of college students was extracted with the proper coordination, and then the number and ratio of female students of each faculty to the whole university were determined. So that faculty with more students were assigned a larger sample size. Also, the sex ratio was considered in the number of samples of each faculty. In the following, the samples were randomly assigned to each faculty.

The inclusion criteria comprised studying in Hamadan University of Medical Sciences and passed at least one semester. Also, students should be members of one of the virtual social networks and have access to the Internet at least 1 hour per day. The exclusion criteria were dissatisfaction with participation in the study. The present study was approved by the Ethics Committee of Hamadan University of Medical Sciences and registered with the Code of ethics IR.UMSHA.REC.1395.161.

In this study, two standard questionnaires were used to collect data: motivation to use a virtual social network [13] and scale for social capital in an online era [14]. Both questionnaires are self-report and completed by students after obtaining their informed consent.

At first, the researchers collected the students' demographic and background information, including age, 
gender, marital status, education level, the field of study, parent's job, parental education level, residence, major academic degree, conditional condition, family monthly income, nativeness, daily use of the virtual social network.

Gülnar et al. (2010) questionnaire was used to collect data about the motivation to use virtual social networks [13]. Seven subscales assessed the motivation of using a virtual social network with 33 questions. These seven subscales consisted of self-disclosure (8 questions), immersion in the media (7 questions), pastime (5 questions), information search (5 questions), individual status (3 questions), maintaining relationships (3 questions), and entertainment (2 questions). For example, one of the items of this questionnaire was "to make a romantic relationship". To answer this question, the scores of 5 to 1 were assigned that corresponds to answers of "I strongly agree", "I agree", "I have no idea", "I disagree", "and I strongly disagree". The total scores range from 33 to 165 . The validity and reliability of this questionnaire have been examined and verified by Moradi and associates [15].

The second questionnaire was the internet social capital scales. Williams designed and standardized this questionnaire [14]. The questionnaire consisted of 10 questions in the area of bonding social capital and 10 questions for bridging social capital. The answers were scored based on a 5-point Likert-type consisting of 1 . strongly disagree; 2. disagree; 3 . no ideas; 4. agree; 5. strongly agree. One of the questions of this questionnaire was the sentence, "I'm sure that there are many people in the virtual social network and help me solve my problems". To find the questionnaire's validity, we used the Content Validity Ratio (CVR) and Content Validity Index (CVI). The questionnaire was presented to 10 health promotion and education and psychology professionals to review the questions for assessing the CVR and identifying the questions that obtained the required score. For CVI, relevance, simplicity, and transparency criteria were examined. All items obtained scores of more than $79 \%$. So, it was found that the questionnaire had good content validity. To confirm the reliability of the questionnaire, we calculated the Cronbach alpha coefficient. A sample of 30 students completed the questionnaire, and the Cronbach alpha coefficient was found as 0.76 .

After collecting data and entering them into SPSS V. 24, the descriptive information was reported using mean descriptive indexes. In the next step, the data were analyzed by the Pearson correlation and linear regression at a significance level of 0.05 .

\section{Results}

The responsiveness percentage of female students participating in the study was $100 \%$. Table 1 presents the demographic characteristics of the subjects. The students in the age group of 20-25 years had the highest frequency (59.7\%). Out of 350 participants, $71.7 \%$ were female, and $84.9 \%$ were single. More than half of the students $(60 \%)$ were studying at the BS level. Many participants (24.4\%) were in medicine. Almost $55.7 \%$ of the participants lived in a dormitory. The education levels of the parents of the students were university education (35.1\%) and below diploma (40.0\%). The parents' employment status was mostly self-employment (30.6\%) and housewives (77.1\%). Most students (83.5\%) had family members of 4 and 6 . The majority of students (88.9\%) were born and brought up in the urban area. $10 \%$ of students had a conditional record. About $42.6 \%$ of the students used their virtual social network 3-5 hours a day. The average family monthly income of many participants (49.1\%) was more than 15000000 Iranian Rials.

Among the studied factors, the entertainment and pastime with $59 \%$ and $58.8 \%$ of the mean score of the maximum achievable score were the most reported reasons for using virtual social networks. Self-disclosure factors with $39.9 \%$ of the mean score of the maximum possible score had the lowest rate. Bonding social capital (42.4\%) and bridging social capital (58.6\%) were evaluated at a moderate level among students (Table 2).

According to Table 3, the virtual social network has a positive and significant correlation with all subscales for the motivation to use the virtual social network. Also, the use of virtual social networks had a positive and significant relationship with the bonding social capital and bridging social capital.

Table 4 presents the analysis of the linear regression test. In total, demographic characteristics and social capital explained $96 \%$ of the motivation to use virtual social network variance among the studied students. Among the related factors, gender, nativeness, self-disclosure, immersion in the media, pastime, information search, individual status, maintaining relationships, entertainment, and bonding social capital had a significant contribution to explaining the motivation to use of virtual social network variance $(P<0.05)$. 
Table 1. Demographic and background characteristics of the participants $(N=350)$

\begin{tabular}{|c|c|c|c|}
\hline Variables & Characteristics & No. & $\%$ \\
\hline \multirow{4}{*}{ Age (y) } & $<20$ & 99 & 28.3 \\
\hline & $20-25$ & 209 & 59.7 \\
\hline & $36-30$ & 33 & 9.4 \\
\hline & $\geq 31$ & 9 & 2.6 \\
\hline \multirow{2}{*}{ Gender } & Male & 99 & 28.3 \\
\hline & Female & 251 & 71.7 \\
\hline \multirow{3}{*}{ Academic degree } & $\mathrm{BSC}$ & 207 & 60.0 \\
\hline & MSc & 80 & 22.9 \\
\hline & GP \& PhD & 60 & 17.1 \\
\hline \multirow{2}{*}{ Marital status } & Married & 53 & 15.1 \\
\hline & Single & 297 & 84.9 \\
\hline \multirow{4}{*}{ Father education level } & Illiteracy & 15 & 4.3 \\
\hline & Below diploma & 97 & 27.7 \\
\hline & Diploma & 115 & 32.9 \\
\hline & Academic degree & 123 & 35.1 \\
\hline \multirow{4}{*}{ Maternal education level } & Illiteracy & 31 & 8.9 \\
\hline & Below diploma & 140 & 40 \\
\hline & Diploma & 88 & 25.1 \\
\hline & Academic degree & 91 & 26.0 \\
\hline \multirow{5}{*}{ Father occupation status } & Self-employed & 107 & 30.6 \\
\hline & Employed & 89 & 25.4 \\
\hline & Retired & 92 & 26.3 \\
\hline & Unemployed & 6 & 1.7 \\
\hline & Farmer and worker & 56 & 16.0 \\
\hline \multirow{2}{*}{ Maternal occupation status } & Housewife & 270 & 70.1 \\
\hline & Working & 80 & 22.9 \\
\hline \multirow{6}{*}{ Major } & Medicine & 91 & 26.0 \\
\hline & Pharmacy & 15 & 4.3 \\
\hline & Dentistry & 33 & 9.4 \\
\hline & Nursing and midwifery & 75 & 21.4 \\
\hline & Paramedical & 55 & 15.7 \\
\hline & Health sciences & 81 & 23.0 \\
\hline \multirow{2}{*}{ Nativeness } & Native & 155 & 44.3 \\
\hline & Non-native & 195 & 55.7 \\
\hline \multirow{5}{*}{ location of life } & Urban & 311 & 88.9 \\
\hline & Rural & 39 & 11.1 \\
\hline & Conditional condition & & \\
\hline & I have & 35 & 10.0 \\
\hline & I do not have & 315 & 90.0 \\
\hline \multirow{4}{*}{$\begin{array}{l}\text { Daily use of the virtual social networks } \\
\text { (h) }\end{array}$} & $<2$ & 73 & 20.8 \\
\hline & $3-5$ & 149 & 42.6 \\
\hline & $6-9$ & 85 & 24.3 \\
\hline & $>9$ & 43 & 12.4 \\
\hline
\end{tabular}




\begin{tabular}{cccc}
\hline Variables & Characteristics & No. & \% \\
\hline & $<1000000$ & 38 & 10.9 \\
Family monthly income (Iranian Rials) & $1000000-1500000$ & 140 & 40.0 \\
& $<1500000$ & 172 & 49.1 \\
\hline
\end{tabular}

AJNPP

Table 2. Mean $\pm S D$ and the average percentage of the maximum achievable score of study variables

\begin{tabular}{cccc}
\hline Variables & Mean \pm SD & Acquired Score & Average Percentage of Maximum \\
Range & Achievable Score & 39.09 \\
\hline Self-disclosure & $20.51 \pm 6.41$ & $8-40$ & 45.96 \\
\hline Immersion in the media & $19.87 \pm 5.74$ & $7-35$ & 58.80 \\
Pastime & $16.76 \pm 4.33$ & $5-25$ & 56.70 \\
\hline Information search & $16.34 \pm 4.04$ & $5-25$ & 45.08 \\
\hline Individual status & $8.41 \pm 2.60$ & $3-15$ & 53.33 \\
\hline Maintaining relationships & $9.40 \pm 2.40$ & $3-15$ & 59.00 \\
Entertainment & $6.72 \pm 1.87$ & $10-50$ & 42.45 \\
\hline Bonding social capital & $26.98 \pm 5.91$ & $10-50$ & 58.66 \\
\hline Bridging social capital & $33.47 \pm 6.90$ & 5 & 5 \\
\hline
\end{tabular}

AJNPP

\section{Discussion}

This research was conducted to determine the effective factors in motivation to use of the mobile virtual networks and their associated social capital in students of Hamadan University. In this study, $63.4 \%$ of partici- pants used the Internet for 0-5 hours a day, which was consistent with the results of similar studies $[2,12]$. The results of studies have shown that higher participation and activity of users in virtual networks results in increasing the common norms and values and the social capital of these individuals, and vice versa [16]. People

Table 3. The associations between subscales the motivation use of the virtual social network with internet social capital

\begin{tabular}{|c|c|c|c|c|c|c|c|c|c|c|}
\hline Variables & 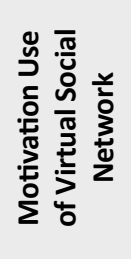 & 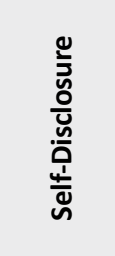 & 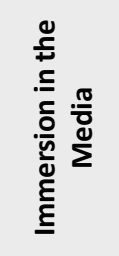 & 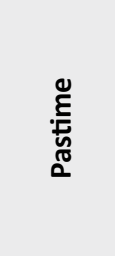 & 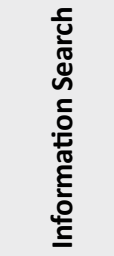 & $\begin{array}{l}\frac{n}{3} \\
\frac{1}{\pi} \\
\frac{\omega}{\pi} \\
\frac{\pi}{0} \\
\frac{0}{2} \\
\frac{2}{0}\end{array}$ & 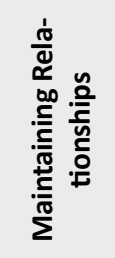 & 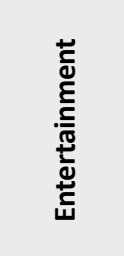 & 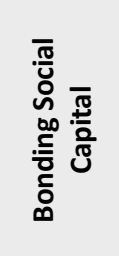 & 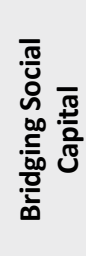 \\
\hline $\begin{array}{l}\text { Motivation use of virtual } \\
\text { social network }\end{array}$ & 1 & & & & & & & & & \\
\hline Self-disclosure & $0.182^{* *}$ & 1 & & & & & & & & \\
\hline Immersion in the media & $0.268^{* *}$ & $0.651^{* *}$ & 1 & & & & & & & \\
\hline Pastime & $0.207 * *$ & $0.298 * *$ & $0.584 * *$ & 1 & & & & & & \\
\hline Information search & $0.115^{*}$ & $0.274^{* *}$ & $0.482^{* *}$ & $0.634^{* *}$ & 1 & & & & & \\
\hline Individual status & $0.138 * *$ & $0.546 * *$ & $0.560 * *$ & $0.413^{* *}$ & $0.481^{* *}$ & 1 & & & & \\
\hline Maintaining relationships & $0.109 *$ & $0.384 * *$ & $0.513^{* *}$ & $0.437 * *$ & $0.461 * *$ & $0.466 * *$ & 1 & & & \\
\hline Entertainment & $0.200 * *$ & $0.314^{* *}$ & $0.549 * *$ & $0.919 * *$ & $0.619 * *$ & $0.390 * *$ & $0.584^{* *}$ & $0.432 * *$ & & \\
\hline Bonding social capital & $0.165^{* *}$ & $0.456 * *$ & $0.354^{* *}$ & 0.047 & $0.323^{* *}$ & 0.072 & $0.177^{* *}$ & $0.326^{* *}$ & 1 & \\
\hline Bridging social capital & $0.228 * *$ & $0.317^{* *}$ & $0.431^{* *}$ & $0.444^{* *}$ & $0.367^{* *}$ & $0.425^{* *}$ & $0.329 * *$ & $0.395^{* *}$ & $0.511^{* *}$ & 1 \\
\hline
\end{tabular}


Table 4. Predicting the motivation use of virtual social network using linear regression analyses (Adjusted R2=0.957)

\begin{tabular}{|c|c|c|c|c|c|c|}
\hline \multirow{2}{*}{ Variables } & \multirow{2}{*}{$\boldsymbol{\beta}$} & \multirow{2}{*}{ B } & \multirow{2}{*}{ SE } & \multicolumn{2}{|c|}{$95 \% \mathrm{Cl}$} & \multirow{2}{*}{$\mathbf{P}$} \\
\hline & & & & Lower & Upper & \\
\hline Age $(y)$ & 0.01 & 0.09 & 0.18 & -0.27 & 0.46 & 0.615 \\
\hline Gender & -0.04 & -1.96 & 0.54 & -3.03 & -0.89 & 0.001 \\
\hline Marital status & 0.01 & 0.06 & 0.74 & -1.38 & 1.51 & 0.930 \\
\hline Academic degree & -0.03 & -1.41 & 0.74 & -2.86 & 0.04 & 0.057 \\
\hline Nativeness & -0.05 & -1.66 & 0.83 & -3.29 & -0.04 & 0.044 \\
\hline Father education level & -0.01 & -0.08 & 0.31 & -0.68 & 0.52 & 0.794 \\
\hline Maternal education level & 0.01 & 0.06 & 0.30 & -0.53 & 0.65 & 0.841 \\
\hline Father occupation status & -0.01 & -0.03 & 0.126 & -0.28 & 0.22 & 0.794 \\
\hline Maternal occupation status & -0.01 & -0.25 & 0.64 & -1.51 & 1.00 & 0.692 \\
\hline Residence & -0.01 & -0.13 & 0.77 & -1.65 & 1.38 & 0.863 \\
\hline Conditional condition & -0.01 & -0.67 & 0.87 & -2.39 & 1.04 & 0.442 \\
\hline Major & -0.02 & -0.28 & 0.25 & -0.77 & 0.21 & 0.254 \\
\hline Daily use of virtual social network & -0.01 & -0.01 & 0.07 & -0.15 & 0.17 & 0.877 \\
\hline Family monthly income & -0.01 & -0.11 & 0.38 & -0.86 & 0.64 & 0.771 \\
\hline Self-disclosure & 0.15 & 1.41 & 0.14 & 1.25 & 1.78 & 0.001 \\
\hline Immersion in the media & 0.42 & 1.52 & 0.06 & 1.40 & 1.64 & 0.001 \\
\hline Pastime & 0.13 & 0.60 & 0.15 & 0.32 & 0.89 & 0.001 \\
\hline Information search & 0.18 & 0.98 & 0.08 & 0.745 & 1.07 & 0.001 \\
\hline Individual status & 0.20 & 1.60 & 0.12 & 1.34 & 1.81 & 0.001 \\
\hline Maintaining relationships & 0.13 & 1.14 & 0.12 & 0.90 & 1.38 & 0.001 \\
\hline Entertainment & 0.16 & 1.75 & 0.32 & 1.13 & 2.39 & 0.001 \\
\hline Bonding social capital & 0.06 & 0.19 & 0.05 & 0.09 & 0.29 & 0.001 \\
\hline Bridging social capital & -0.01 & -0.01 & 0.04 & -0.08 & 0.08 & 0.967 \\
\hline
\end{tabular}

$\mathrm{N}=350$

AJNPP

ß: Beta; B: unstandardized regression coefficient; SE: Standard Error

who use virtual networks spend a few hours in study, and this impedes their academic performance [17]. According to a survey, $53 \%$ of the total population of Iran were members of at least one virtual social network. In this regard, the most commonly used virtual network by the Iranian users is Telegram application with the traffic of $30.8 \%$. Among the countries of the world, Iranians rank the first in this field. Also, educated people use virtual networks more than common people [2].

With the development of different mass media, the people can choose and use their intended media, based on their interests, needs, and circumstances [18]. In various studies, researchers have reported different motivations to use virtual networks. In some studies, the factor of maintaining relationships has been mentioned, which is related to the theory of social influence and the effect of the relationship on the formation of our concept in cyberspace. People in cyberspace mostly seek to form the groups, and when individuals in this space find similar values with other groups, they get more motivated in line with our concept about the cyberspace. Also, in some studies, entertainment was the strongest motivation to use cyberspace [19-21]. In one study, about two-thirds of students who used the virtual networks had almost 10 friends and, of those, 4 were the opposite sex. This finding is in line with the factor of maintaining the relationships [18].

Two processes, i.e. domestication and mediatization, indicate that most of the leisure time of young people in modern societies is spent on virtual networks. Young people spend most of their time in private and increasingly use the Internet and virtual spaces to entertain themselves [22]. On the other hand, given the time that students assign to social media, their academic performance declines. Moreover, the adverse effects associated with these networks such as stress 
and anxiety, are observed among the students. However, these virtual networks can also have positive outcomes and, by the proper use of these spaces, it is possible to take steps towards educational goals [1].

In another study, they concluded that the bridging social capital is stronger in cyberspace and that bonding social capital is stronger in the real world. With the introduction of virtual networks into the lives of people, the communications have changed from bonding social capital to bridging social capital [2]. In this study, bridging social capital with an average of 33.47 was obtained to be higher than bonding social capital with an average of 98.96, and there was a relationship between bonding social capital and the motivation to use the virtual networks. The results were similar to other studies on this topic [2].

These findings can be due to the type and extent of relationships in social networks. In other words, the primary function of this type of social capital is to facilitate the dissemination of information and strengthening the connection with other resources. This issue can be accessed through virtual networks and channels and numerous professional groups. In a study, it was clarified that $42.2 \%$ of virtual network users have high social connections and links [16]. It has also been clarified that the desire to use social networking services and facilities is effective on the level of using social capital [23].

The results of the studies have shown that virtual networks are a suitable platform for the emergence and formation of social capital, and active people in these networks have higher social capital than non-active users. On the other hand, virtual networks have their norms and rules, e.g., privacy, which is necessary to maintain relationships in these networks. So, it is difficult to identify individuals completely and trust people in virtual networks, and as a result, some of the friendships that take shape in these spaces and lead to marriage will also fail. Researchers believe that greater communication between people in cyberspace provides more chances for people to gain information about each other and more motivation to trust each other [24].

There was a significant relationship between the variables of sex and nativeness with the motivation to use the virtual network. In a study, the motivation to use the virtual network in females was more than males $[18,22]$. In another study, the females applied mobile phones to deepen their relationship with others, and the males used the mobile for educational purposes and software applications and advanced communica- tions and entertainment $[2,25]$. Also, non-native students use virtual networks more than native students. This difference could be because they are away from their family and friends. So they spend more time on these networks.

There was a correlation between all the subscale of study and bridging social capital. Also, bonding social capital is associated with subscales of self-disclosure, immersion in the media, individual status, maintaining relationships, and motivation to use the virtual network. A similar association was found between the two variables of social capital and virtual social networks among participants in the study [26].

There was a significant and direct correlation between communication with others on Facebook and social capital [23]. As communication with others on Facebook increases, the social capital of these communications will also increase. Self-reporting can be pointed out as one of the limitations of this study, so that the subjects may not have complete integrity in answering the questionnaires.

\section{Conclusion}

Further research is necessary in this field because students increasingly use virtual networks while they are unfamiliar with other aspects of these networks that may affect their health and life. The university counseling centers should provide the necessary training based on facts for the students about the positive and negative consequences of using virtual networks.

\section{Ethical Considerations}

Compliance with ethical guidelines

The present study was approved by the Ethics Committee of Hamadan University of Medical Sciences and registered with the Code of Ethics IR.UMSHA. REC.1395.161.

\section{Funding}

This work was supported by Hamadan University of Medical Sciences [Reference number: 9506023160].

\section{Authors' contributions}

All authors contributed in designing, running, and writing all parts of the research. 


\section{Conflict of interest}

The authors declared no conflict of interest.

\section{Acknowledgments}

The Research and Technology Deputy of Hamadan University of Medical Sciences approved this project.

\section{References}

[1] Dastani M, Keramati J, Poorfatemi A, Ekrami A. [The reasons and motives of virtual social networks among students of Gonabad University of Medical Sciences (Persian)]. Caspian Journal of Scientometrics. 2015; 2(2):24-7.

[2] Shaverdi T. [Social capital in the online and offline social networks (the case study: Female university students in Tehran) (Persian)] Social Development. 2017; 11(3):67-96

[3] Grant I, Donohoe S. Why young consumers are not open to mobile marketing communications. International Journal of Advertising. 2007; 26(2):223-46. [DOI:10.1080/10803548.2007.11073008]

[4] Saied SM, Elsabagh HM, El-Afandy AM. Internet and facebook addiction among Egyptian and Malaysian medical students: a comparative study, Tanta University, Egypt. International Journal of Community Medicine and Public Health. 2016; 3:1288-97. [DOI:10.18203/2394-6040.ijcmph20161400]

[5] Soltanifar M. [Modern public diplomacy and electricity public relations (Persian)]. Tehran: Simaye Shargh; 2010.

[6] Navabakhsh M, Hashem Neghad F, Zadesham Pour V. [A study of internet and mobile effects on changes in the identity of the youth (Persian)]. Journal of Social. 2010; 1(1):145-70.

[7] Neelamalar M, Chitra P. New media and society: A study on the impact of social networking sites on Indian youth. Estudos em Comunicacao. 2009; 6(1):125-45.

[8] Shahabi M, Bayat G. [Purposes and motivations of social networks'members (a study on youth from Tehran) (Persian)]. Culture-Communication Studies. 2013; 20 (52):61-86

[9] Akhvan-Malayeri F, Noghani M, Mazloom-Khorasani M. Virtual social network and happiness. Media and Culture Journal. 2014 4(2):1-24.

[10] Massari L. Analysis of my space user profiles. Information Systems Frontiers. 2010; 12(4):361-7. [DOI:10.1007/s10796-009-9206-8]

[11] Chosunil BO. Korea number six internet use [Internet]. 2002 [Updated 2002 Oct 15]. Available from: http//www.chosum.com

[12] Hasanzadeh R. [Internet addiction in students: Threat factor for mental health (Persian)]. Journal of Health System Research. 2010 $1 \cdot 3-4$

[13] Gülnar B, Balci S, Çakir V. Motivations of acebook, You Tube and similar web sites users. Türk Dünyasi Sosyal Bilimler Dergisi. 2010, 54:161-84.
[14] Williams D. On and off the'Net: Scales for social capital in an online era. Journal of Computer-Mediated Communication. 2006; 11(2):593-628. [DOI:10.1111/j.1083-6101.2006.00029.x]

[15] Moradi SH, Rajabpour M, Kianersi F, Hajlo N, Radbakhsh N. [Motivational Factors in Using Virtual Social Networks (Persian)]. Culture in the Islamic University. 2014; 4(10):95-118.

[16] Gholamreza G, Maryam T. Participation and activity in virtual networks and virtual social capital tourism in Iran. Tourism Planning and Development. 2015; 4(14):67-90.

[17] Kirschner PA, Karpinski AC. Facebook ${ }^{\circledR}$ and academic performance. Computers in Human Behavior. 2010; 26(6):1237-45.

[18] Schuller T, Baron S, Field J. Social capital: A review and critic. In: Baron S, Field J, \& Schuller T. ed. Social Capital. Oxford: Oxford University Press; 2000.

[19] Pempek TA, Yermolayeva YA, Calvert SL. College students' social networking xperiences on Facebook. Journal of Applied Developmental Psychology. 2009; 30(3):227-38. [DOI:10.1016/j.appdev.2008.12.010]

[20] Afshari M, Mirzaeii M, Kangavari M, Afshari M. [Students' experiences of the consequences of social networks: A qualitative study (Persian)]. Journal of Qualitative Research in Health Sciences. 2015; 4(3):256-65.

[21] Cheung CM, Chiu PY, Lee MK. Online social networks: Why do students use facebook? Computers in Human Behavior. 2011; 27(4):1337-43. [DOI:10.1016/j.chb.2010.07.028]

[22] Zaki, M. Internet and youth religiosity (Case: 19-30-Year-old girls and boys in Isfahan). Information and Communication Technology in Educational Sciences. 2014; 4(2):21-43.

[23] Azari GR, Omidvar T. [Study the role of social network sites on socia capital (Persian)]. Culture of Communication. 2012; 2(6):181-209.

[24] Cote S, Healy T. The well-being of nations. The role of human and social capital. Paris: Organisation for Economic Co-operation and Development; 2001.

[25] Manteghi M. Studying the use of mobile phone by female and male students. Information and Communication Technology in Educational Sciences. 2011; 1(2):95-128.

[26] Kavousi I, Kazemi H. [The role of virtual social networks pulitical social movement in the formation of social capital cultural aspect (Persian)]. Cultural Management 2013; 4(9):73-94. 